
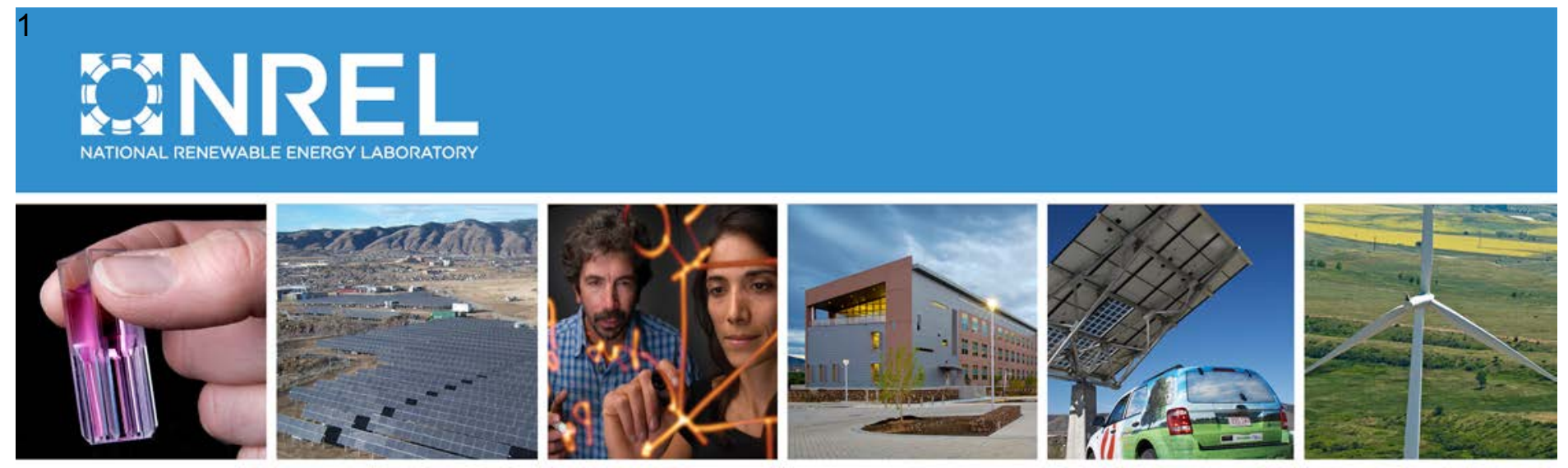

\title{
Job/Task Analysis: Enhancing the Commercial Building Workforce Through the Development of Foundational Materials
}

\section{Preprint}

D. Studer

National Renewable Energy Laboratory

S. Kemkar

U.S. Department of Energy

Presented at the ACEEE Summer Study on Energy Efficiency in Buildings

Pacific Grove, California

August 12-17, 2012

NREL is a national laboratory of the U.S. Department of Energy, Office of Energy Efficiency \& Renewable Energy, operated by the Alliance for Sustainable Energy, LLC.

Conference Paper

NREL/CP-5500-55210

September 2012

Contract No. DE-AC36-08GO28308 


\section{NOTICE}

The submitted manuscript has been offered by an employee of the Alliance for Sustainable Energy, LLC (Alliance), a contractor of the US Government under Contract No. DE-AC36-08GO28308. Accordingly, the US Government and Alliance retain a nonexclusive royalty-free license to publish or reproduce the published form of this contribution, or allow others to do so, for US Government purposes.

This report was prepared as an account of work sponsored by an agency of the United States government. Neither the United States government nor any agency thereof, nor any of their employees, makes any warranty, express or implied, or assumes any legal liability or responsibility for the accuracy, completeness, or usefulness of any information, apparatus, product, or process disclosed, or represents that its use would not infringe privately owned rights. Reference herein to any specific commercial product, process, or service by trade name, trademark, manufacturer, or otherwise does not necessarily constitute or imply its endorsement, recommendation, or favoring by the United States government or any agency thereof. The views and opinions of authors expressed herein do not necessarily state or reflect those of the United States government or any agency thereof.

Available electronically at http://www.osti.gov/bridge

Available for a processing fee to U.S. Department of Energy and its contractors, in paper, from:

U.S. Department of Energy

Office of Scientific and Technical Information

P.O. Box 62

Oak Ridge, TN 37831-0062

phone: 865.576 .8401

fax: 865.576 .5728

email: mailto:reports@adonis.osti.gov

Available for sale to the public, in paper, from:

U.S. Department of Commerce

National Technical Information Service

5285 Port Royal Road

Springfield, VA 22161

phone: 800.553 .6847

fax: 703.605.6900

email: orders@ntis.fedworld.gov

online ordering: http://www.ntis.gov/help/ordermethods.aspx

Cover Photos: (left to right) PIX 16416, PIX 17423, PIX 16560, PIX 17613, PIX 17436, PIX 17721

Printed on paper containing at least $50 \%$ wastepaper, including $10 \%$ post consumer waste. 


\title{
Job/Task Analysis: Enhancing the Commercial Building Workforce Through the Development of Foundational Materials
}

\author{
Daniel Studer, National Renewable Energy Laboratory ${ }^{1}$ \\ Sonal Kemkar, U.S. Department of Energy
}

\begin{abstract}
For many commercial building operation job categories, industry consensus has not been reached on the knowledge, skills, and abilities that practitioners should possess. This raises concerns about the future numbers of qualified, skilled workers who will be available to provide the energy efficiency solutions needed in this sector. Although multiple educational programs currently offer industry practitioners broad access to training, program curricula often differ in terms of content and how job roles are defined. This makes it difficult to identify which training programs fulfill job competency requirements, and prevents wider penetration of effective training programs into the commercial building space.

To lower this barrier, job/task analyses that identify (1) all the major tasks performed in a given job; and (2) the knowledge, skills, and abilities that define the minimum requirements necessary to adequately perform those tasks, have been developed for six commercial buildingspecific job categories: energy auditors, energy modelers, commissioning/retro-commissioning authorities, energy/sustainability managers, facility managers, and operating engineers/building technicians. Our goal is to provide a basis for developing and comparing new and existing training programs, help practitioners identify opportunities to enhance their professional skills, enable industry to identify an appropriately skilled workforce, and enable training providers to deliver the highest quality product possible.

This paper presents an overview of the project drivers, job/task analysis development specifics, a comparative analysis of the material contained within the job/task analyses, and how the job task analyses will benefit commercial building training programs.
\end{abstract}

\section{Introduction}

The commercial building industry has a diverse field of building operations practitioners, and public and private sector organizations have developed a variety of educational programs to train this workforce. Although these programs offer broad access to training, they often vary widely in both content and how job roles and responsibilities are defined. Practitioners who possess certifications in the same job category from two organizations have likely been tested on different materials. This fragmentation (1) makes it difficult to identify which training and certification programs fulfill job competency requirements; and (2) prevents wider penetration of effective workforce development programs into the commercial building space.

\footnotetext{
${ }^{1}$ The Alliance for Sustainable Energy, LLC (Alliance), is the manager and operator of the National Renewable Energy Laboratory (NREL). Employees of the Alliance for Sustainable Energy, LLC, under Contract No. DE-AC36-08GO28308 with the U.S. Dept. of Energy, have authored this work. The United States Government retains and the publisher, by accepting the article for publication, acknowledges that the United States Government retains a non-exclusive, paid-up, irrevocable, worldwide license to publish or reproduce the published form of this work, or allow others to do so, for United States Government purposes.
} 
Building owners and policy and program administrators have also become increasingly aware of the effects practitioner's skills have on building energy use, which has lead to an increase in demand for trained and credentialed practitioners. While the market has legitimateand often compulsory-reasons to provide diverse and numerous training and certification offerings, unless the industry agrees about minimum knowledge and skills that commercial building operations practitioners should possess, it cannot understand which program is best suited to each individual's needs.

To address this issue, the U.S. Department of Energy tasked the National Renewable Energy Laboratory (NREL) to develop job/task analyses (JTAs), which identify (1) the tasks performed in a given job; and (2), the associated knowledge, skills, and abilities (KSAs) - the minimum requirements to adequately perform those tasks. The U.S. Department of Energy sponsored the development of JTAs in six commercial building-specific job categories: commercial building energy auditors, commercial building energy modelers, commissioning/retro-commissioning authorities, energy/sustainability managers, facility managers, and operating engineers/building technicians.

Our goals are to help streamline the minimum competencies taught or tested by organizations catering to building operations and maintenance personnel and to provide a basis for developing and comparing new and existing training programs. The JTAs will help individuals identify opportunities to enhance their professional skills, enable industry to identify an appropriately skilled workforce, and enable training providers, such as the American Society of Heating, Refrigerating and Air-Conditioning Engineers (ASHRAE) and the Association of Energy Engineers (AEE), to further enhance the quality of their offerings.

\section{Defining Job/Task Analysis}

The term $J T A$ can be slightly confusing, as it may be used to describe both a process and the output of that process. JTA as a process, is "any systematic procedure for collecting and analyzing job-related information to meet a particular purpose" (Raymond 2001, 372) and can be defined generally as a practice used to analyze job-related tasks, along with the KSAs required to support the performance of those tasks. The document resulting from the JTA process, also referred to as a JTA, is often used to describe, classify, and evaluate jobs; ensure compliance with legal and quasi-legal requirements; develop training, promote worker mobility, plan workforces, increase efficiency and safety, and appraise performance (Brannick, Levine \& Morgeson 2007, 3-5). Use of the term JTA in this paper refers to a document, rather than the process.

\section{The Job/Task Analysis Development Process}

Each JTA was constructed over the course of approximately 21 months using a sevenstep process. These steps are outlined below, with details about each provided in the subsections that follow:

1. Identify a JTA development method.

2. Retain a group of subject matter experts.

3. Hold the development workshops.

4. Create JTA drafts. 
5. Facilitate a public comment period.

6. Survey validation.

7. Incorporate comments and publish final JTAs.

\section{Identify a JTA Development Method (October 2010-January 2011)}

To have the desired influence in the commercial building training and certification space, the content of each JTA needed to be technically accurate and the development process had to instill confidence in the marketplace that the process would lead to the production of a valid, trustworthy, and unbiased document. The JTAs were thus developed in accordance with ANSI/ISO/IEC 17024 - General requirements for bodies operating certification schemes for persons (ANSI 2003), hereafter referred to as ANSI 17024. This standard, which was developed "with the objective of achieving and promoting a globally accepted benchmark for bodies managing the certification of persons" (ANSI 2012) presents a series of development and managerial practices that an organization must follow to attain and maintain accreditation under the standard.

One requirement is to develop and maintain a certification scheme, which is used to create the certification examination; it is recommended that this be based on a JTA. Although the scope of this project did not extend to the development of certification examinations or programs, maintaining consistency with ANSI 17024 ensured the JTAs were developed using a vetted, quality, and industry-accepted process. An added benefit is that interested organizations have the option to leverage the JTAs for use in their own ANSI-accredited certification programs. ANSI 17024 does not, however, mandate a method to develop the JTA. While many methods exist, the Developing a Curriculum (DACUM) process was chosen for this project because it requires active job practitioners to be part of the development process.

The DACUM method is a "storyboarding process that provides a picture of what the worker does in terms of duties, tasks, knowledge, skills, traits and in some cases the tools the worker uses" (DACUM.org 2001). The process uses a trained DACUM facilitator to lead a group of active job practitioners (individuals who are currently employed in the job being analyzed) through a structured, multiday workshop, the result of which is a draft JTA. The content of each developed JTA was thus created by industry, for industry, thereby alleviating any inherent dictatorial or ivory-tower type biases that may have been present had the JTAs been developed by persons who were not active in the job categories.

Certification as a DACUM facilitator has no prerequisites (OSU 2012); however, this project used DACUM-certified professional psychometricians (experts in the field of psychological measurement) to facilitate the overarching DACUM process and the individual DACUM development workshops. These psychometricians were also experts with regard to ANSI 17024, and their role helped to ensure consistency with that standard.

\section{Retain a Group of Subject Matter Experts (February-April 2011)}

Industry practitioners who were interested in participating in the JTA development workshops were invited to submit applications via a publically available website (Professional Testing, Inc. 2011). Applicants were required to supply the following information:

- $\quad$ Contact (name, phone number, and email) 
- Organization (employer)

- $\quad$ Sector (whether their employer was a public or private sector organization)

- $\quad$ Organization size (number of employees)

- $\quad$ Primary work location (city, state)

- $\quad$ Area of specialty (which of the six job categories they identified with)

- Years of practice

- $\quad$ Professional memberships held

- $\quad$ Professional credentials held

- Resume

Qualified industry practitioners were selected based on the applicants' ability to prove they were current practitioners in their specified fields.

Once the applicant pool was reduced to qualified, active practitioners, psychometricians further down-selected the applicants, with the goal of obtaining a group of no more than 12 practitioners for each job category. DACUM groups are usually limited to 12-15 individuals to facilitate an effective exchange of ideas; larger groups tend to have difficulty agreeing. The psychometricians made their selections carefully to ensure

- $\quad$ The participants were from diverse geographic regions

- $\quad$ A wide range of experience levels were represented (novice through expert)

- $\quad$ The group was not dominated by a single organization or organization size

- $\quad$ No single sector dominated (public versus private)

- A diversity of industry-related credentials was represented

This selection method resulted in a qualified group, rather than a set of qualified individuals. Thus, if an originally selected applicant was unable to attend the JTA development workshop, every attempt was made to replace that person with a "like" individual.

\section{Hold the JTA Development Workshops (May-June 2011)}

Each participant traveled to the Denver metro area, where the JTA development workshops were held during summer 2011. Table 1 provides an overview of when each workshop was held and how many participants attended.

Table 1. Overview of JTA Development Workshops

\begin{tabular}{|l|c|c|}
\hline \multicolumn{1}{|c|}{ Job Category } & Workshop Dates & Number of Participants \\
\hline Commercial Building Energy Auditor & May 11-13,2011 & 12 \\
\hline Commercial Building Energy Modeler & June 7-9, 2011 & 11 \\
\hline Commissioning/Retro-Commissioning Authority & May 11-13, 2011 & 10 \\
\hline Energy/Sustainability Manager & May 24-26, 2011 & 12 \\
\hline Facility Manager & June 7-9, 2011 & 6 \\
\hline Operating Engineer/Building Technician & May 11-13, 2011 & \\
\hline
\end{tabular}

Source: NREL 2012a, 2012b, 2012c, 2012d, 2012e, 2012f 
Because each workshop followed the DACUM process, each workshop was structured the same way and as can be noted from Table 1, lasted three days.

The first part of workshop day 1 was devoted to identifying duty areas, "large area(s) of work for a specific profession" (DOE 2011,6). As an example, one duty area identified during the commercial building energy auditor JTA development workshop was "inspecting building conditions and operations" (DOE 2011,9). After the participants were finished identifying duty areas, they identified the job tasks that were required under each duty area. Each job task was required to consist of a verb, a modifier, and a noun; in general the tasks were high level. For example, only eight tasks were identified under the "inspecting building conditions and operations" duty area, one of which was "conduct building envelope audit" (DOE 2011, 9).

Day 2 was devoted to identifying the knowledge, skills, abilities, tools, and the specific steps necessary to accomplish each identified task. In general, this was the most time-intensive piece of each workshop, as many steps were identified as necessary for the completion of most tasks. For the "conduct building envelope audit" task, 12 steps were identified, along with 10 knowledge areas, six skills and abilities, and two types of tools, equipment, and resources (DOE 2011, 31).

Some time on the third and final day of each workshop was allotted as makeup in case either of the previous days' activities ran over. Once all the task steps, knowledge, skills, abilities, and tools were identified, the participants were asked to weight each task by rating how often they performed each task and how important that task was to overall job success. Another part of day 3 was set aside to allow the participants to create a one-sentence job description. This description was attached to the final JTAs to provide context to the reader, since most jobs are known by many titles.

\section{Facilitate a Public Comment Period (July-November 2011)}

Each JTA underwent two separate reviews to ensure accurate descriptions. The first was a public comment period, in which DOE solicited comments from the public through the Federal Register (NARA 2011). The public comment period was opened on October 14, 2011 and closed at 5:00 p.m. eastern time on November 28, 2011. Table 2 summarizes the number of comments for each JTA.

Table 2. Overview of Public Comment Responses

\begin{tabular}{|l|c|c|}
\hline \multicolumn{1}{|c|}{ Job Category } & Number of Commenters & Number of Comments \\
\hline Commercial Building Energy Auditor & 11 & 33 \\
\hline Commercial Building Energy Modeler & 15 & 49 \\
\hline Commissioning/Retro-Commissioning Authority & 9 & 57 \\
\hline Energy/Sustainability Manager & 33 & 89 \\
\hline Facility Manager & 32 & 156 \\
\hline Operating Engineer/Building Technician & 23 & 135 \\
\hline
\end{tabular}

\section{Survey Validation (December 2011-March 2012)}

The second review was a survey validation, a targeted survey that is a standard part of the DACUM process. Its purpose was to ensure the original workshop participants' delineation of the professional role and the associated weighting factors were correct. Survey validation 
ensured that tasks were not included erroneously, that no tasks were overlooked by the workshop participants, and that the weighting factors for each task were correct.

The first section of each validation survey posed a series of demographic questions to help the workshop participants evaluate if the respondent cohort sample appropriately represented the targeted population. The following demographic questions were posed to respondents to the survey validation; responses to all were mandatory:

- What is the size of your organization?

- In which state do you work?

- In which sector do you currently work?

- Which of the following jobs have you held in the commercial building sector?

- Commercial Building Energy Auditor

- Commissioning/Retro-Commissioning Authority

- Commercial Building Energy Modeler

- Energy/Sustainability Manager

- Facility Manager

O Operating Engineer/Building Technician

o None

- Which of the following categories best describes your current position?

- [INSERT JOB CATEGORY] Practitioner

[ [INSERT JOB CATEGORY] Curriculum Developer

- [INSERT JOB CATEGORY] Trainer/Proctor

Other (please specify)

- How many years of experience have you had working as a/an [INSERT JOB CATEGORY] (total combined years)?

- How many years of total experience do you have in the commercial building industry (all jobs)?

- What is your highest completed level of education?

- What professional societies/organizations do you belong to?

- What commercial building credentials do you currently hold?

Each respondent was then presented with a list of the tasks identified by the workshop participants and asked to rate each based on (1) how frequently it was performed (never, occasionally, fairly often, or very often); and (2) how important that task was to performance of the job (not important, somewhat important, important, or very important). The responses to each question were combined to create a single, weighted value for each task. Respondents were also afforded the opportunity to identify any tasks that were missing and provide comments.

Extensive outreach was performed to provide industry ample opportunity to comment on these documents. Table 3 summarizes the number of practitioners notified, either through direct email or through postings to relevant LinkedIn ${ }^{\circledR}$ groups, that the JTAs were available for survey validation and the corresponding number of responses received. 
Table 3. Survey Validation Outreach and Response Rates

\begin{tabular}{|l|c|c|}
\hline \multicolumn{1}{|c|}{ Job Category } & $\begin{array}{c}\text { Number of Practitioners } \\
\text { Notified }\end{array}$ & $\begin{array}{c}\text { Number of } \\
\text { Responses }\end{array}$ \\
\hline Commercial Building Energy Auditor & 5,242 & 69 \\
\hline Commercial Building Energy Modeler & 3,469 & 64 \\
\hline Commissioning/Retro-Commissioning Authority & 3,782 & 61 \\
\hline Energy/Sustainability Manager & 11,762 & 55 \\
\hline Facility Manager & 31,666 & 247 \\
\hline Operating Engineer/Building Technician & 4,113 & 250 \\
\hline
\end{tabular}

\section{Incorporate Comments and Publish Final JTAs (April-June 2012)}

At least $50 \%$ of the original workshop participants in each job category were reconvened via teleconference and asked to review the survey validation statistical results, individual survey responses, and public comments. Each teleconference was facilitated by a psychometrician who presented the statistical results and comments to the group and modified the JTA whenever the participants felt that modification was warranted to address the comment. This method of incorporating comments was necessary for the final JTAs to be consistent with ANSI 17024 (ANSI 2003).

A psychometrician then incorporated relevant documentation and statistics related to the survey validation and public comment period into each document. This content included demographic information about the survey validation respondents, details related to survey validation responses, and a discussion of the changes (if any) that the JTA development workshop participants incorporated into the final document. The resulting documents were then delivered to NREL for publication. The reference section of this report provides citation information for all six published documents.

\section{Job/Task Analysis Results Overview}

Of all the information contained in each JTA, the content of each DACUM chart is arguably the most important. This table is included as part of Appendix B in each JTA, and contextually lists the duty areas, tasks, steps, and the associated specialized KSAs, and tools, equipment and resources identified as critical to successful job performance. An organization looking to develop or modify a training or certification program would use this table to determine which topics the curriculum should cover (using the final content blueprint, also included as part of each JTA, as a guide for how much time should be spent on each topic).

Examination of the DACUM charts from each JTA led to two interesting observations:

- $\quad$ Areas of direct overlap were found between certain jobs. For example Table 4, which facilitates comparison of commercial building energy auditor task C.3 to commissioning/retro-commissioning authority task A.3, shows a remarkable similarity between these two tasks, as illustrated by the commonality of many subservient steps.

- $\quad$ Such areas of overlap do not always occur at the same level of detail. For instance, Table 5 shows that several steps identified as part of commercial building energy modeler task B. 4 are listed as tasks in the commercial building energy auditor JTA. 
Table 4. Comparison of Commercial Building Energy Auditor Task C.3 and Commissioning/Retro-Commissioning Authority Task A.3

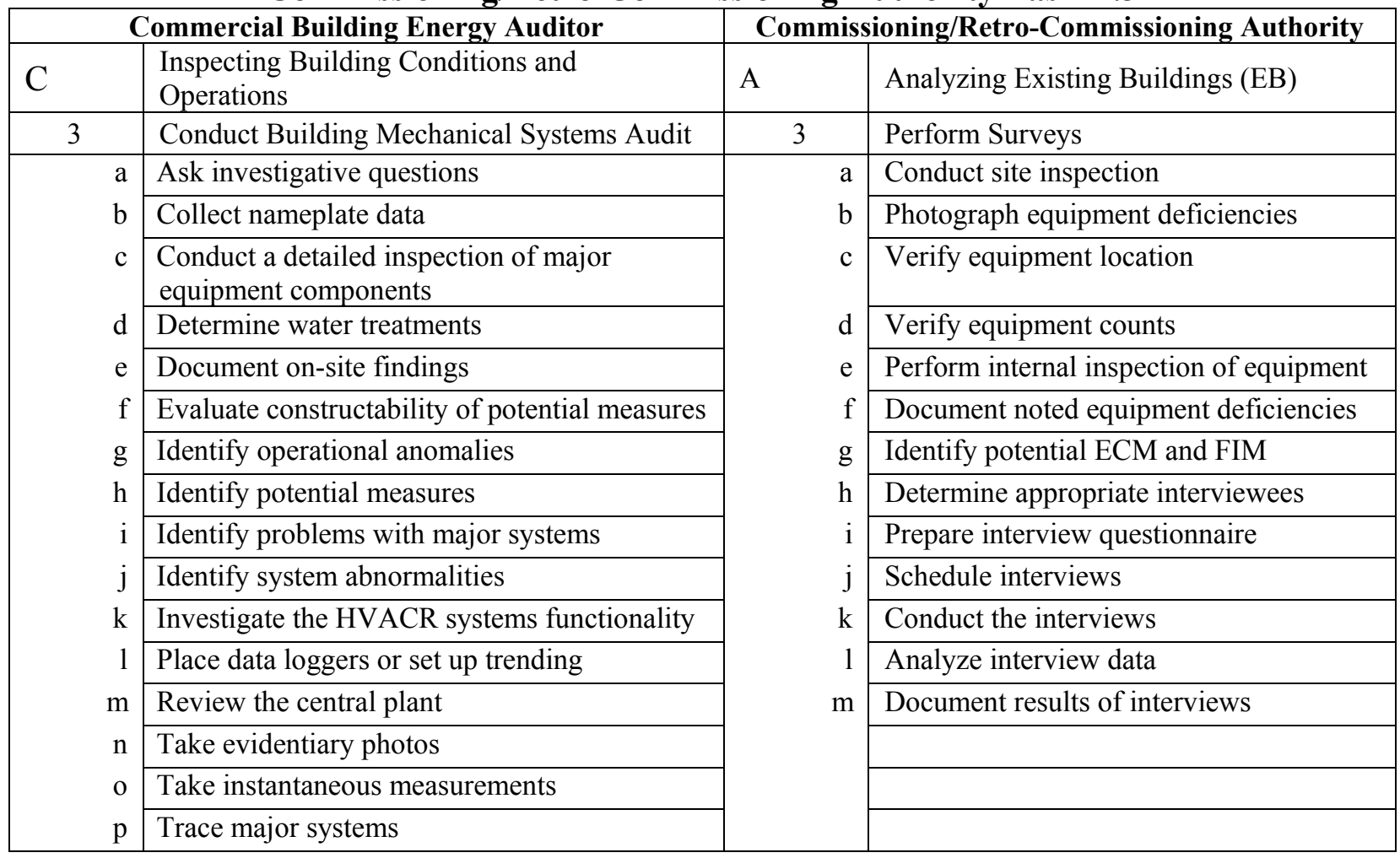

Sources: NREL 2012a, 2012c

Table 5. Comparison of Select Commercial Building Energy Auditor Tasks and Commercial Building Energy Modeler Task B.4

\begin{tabular}{|c|c|c|c|}
\hline \multicolumn{2}{|r|}{ Commercial Building Energy Auditor } & \multicolumn{2}{|r|}{ Commercial Building Energy Modeler } \\
\hline B & Collecting and Reviewing Preliminary Data & B & Gathering Data \\
\hline 7 & Develop Preliminary Audit Plan & 4 & Collect On-site Data (existing building) \\
\hline $\mathrm{C}$ & Inspecting Building Conditions and Operations & $\mathrm{a}$ & Develop onsite data collection plan \\
\hline 2 & Conduct Building Envelope Audit & $\mathrm{b}$ & Determine lighting power \\
\hline 3 & Conduct Building Mechanical Systems Audit & \multirow{2}{*}{$\begin{array}{l}c \\
d\end{array}$} & Assess plug loads \\
\hline 4 & Conduct Building Interior Audit & & Assess HVAC system \\
\hline 6 & Conduct Interior/Exterior Building Lighting Audit & e & Assess building envelope characteristics \\
\hline & & \multirow{2}{*}{$\begin{array}{l}\mathrm{f} \\
\mathrm{g}\end{array}$} & Catalog equipment \\
\hline & & & Perform spot/short term measurements \\
\hline
\end{tabular}

Sources: NREL 2012a, 2012b

Overall, this coincidence of critical tasks and steps implies that for certain jobs in the commercial building space, the development of laddered training and credentialing programs may be appropriate for certain jobs. Such programs could use a structure that focuses on key core modules to impart skills of common interest to the workforce (as another example, utility bill analysis and document/plan review tasks were prevalent among the six examined jobs). Then tiered courses could be developed to impart supplementary skills at the appropriate level.

Training or credentialing systems of this type would provide significant benefits over the traditional, siloed approach commonly available to workers in the commercial building sector. Primary among them would be increased access to training and enhanced worker mobility. By 
eliminating duplicative content through the development of core modules and using tailored supplemental modules that focus on job-specific skills at the appropriate level, commercial building industry professionals would be able to reduce the realized cost of acquiring jobrelevant skills by paying only for the training or certification they want or need.

By lowering the fiscal barrier to training and certification, not only would practitioners be afforded easier access, but more practitioners would be encouraged to pursue such skillenhancing pathways. This could result in a more educated workforce and, by cultivating a larger overall trainee pool, in additional revenue for training and certification providers. Also, the use of tailored supplemental modules would provide a clear series of steps for incumbent workers to obtain the incremental skills that would allow them to move from job to job within the commercial building industry.

Significant work remains to be done before such programs can be developed. The pathways and areas of commonality between all commercial building-related jobs of interest must be comprehensively mapped. Thorough examination of the duty areas, tasks, and steps contained in the six JTAs referenced in this paper represents a logical and appropriate starting point for such an analysis; however, considerable further work, including the development of JTAs for additional job categories, would likely be necessary to properly identify all relevant pathways in the commercial building sector. Additionally, the development and examination of JTAs in related fields, such as the residential building sector, could identify logical and robust pathways for workers to transition effectively between relevant industries.

\section{Next Steps}

Building owners, state and local policymakers, and program administrators are increasingly implementing measures and mandates to facilitate the adoption of energy performance ratings, energy audits, and retro-commissioning of existing commercial buildings. Many of these measures require the work to be performed by a certified practitioner, which supports an increased need for a trained and certified workforce. The required certifications often vary widely between programs though, because managing personnel do not have access to standardized information about the content and availability of certification programs. Therefore, they cannot easily evaluate what minimum skills trained or credentialed practitioners possess.

Also, because of the current lack of guidelines or standards for commercial building operation practitioners, developers of energy efficiency legislation, mandates, and programs currently perceive that credentials alone are not enough, leading to the need to set further requirements, such as stipulations for minimum professional experience and additional review by licensed design professionals. These requirements add cost and complexity, slowing the implementation of energy efficiency initiatives and potentially excluding many workers who are capable of performing the work. This variance in requirements is also a barrier to building owners and workers. Building owners who own property in multiple jurisdictions cannot create a companywide policy on worker certifications to meet these requirements, and workers must invest in multiple certifications to service different locations.

A set of national guidelines or standards would lead to training and certification programs that have improved quality and are transferable across the nation and among employers. A training and certification provider coalition could act as a platform for industry to discuss, adopt, and maintain guidelines such as the JTAs. Adoption of the JTAs would lead to an increase in the market value of training and credentialing programs, increased transparency on what is taught or 
examined, and ensure a higher level of information is provided to workers investing in such programs.

In order for workers to confidently invest in a national training or credentialing program however, the program should

- $\quad$ Be meaningful. Teach or certify skills that are directly linked to job responsibilities

- $\quad$ Provide quality assurance. Maintain third-party accreditation to ensure organizational best practices and transparency and standardization of curriculum/exam materials

- $\quad$ Be transferable. Structure curricula to ensure national transferability of qualifications and increase value to trainees

- Have local/regional training centers. Provide an accessible pool of knowledgeable trainers so trainees have local access to nationally recognized training/credentials

By following a process that included a diverse set of practitioners from across the United States and a public comment and survey validation, the JTAs can act as unbiased foundational materials for a new approach to creating national training and certification programs. If the national training industry can agree on the use of these materials to streamline the minimum competencies taught or examined, practitioners will have a transparent way to show they possess the skill set necessary to produce high-quality work and meet the highest possible level of energy efficiency in building operations.

\section{Acknowledgement}

This work was financially supported by the U.S. Department of Energy Building Technologies Program, under Task Number BEC7.1330. The authors thank the BTP team for its dedicated support of this project. The authors also thank the staff of Professional Testing, Inc.; their patience, dedication, and psychometric acumen made this project possible.

\section{References}

[ANSI] American National Standards Institute. 2003. ANSI/ISO/IEC 17024 - General requirements for bodies operating certification schemes for persons. Washington, D.C.: American National Standards Institute.

[ANSI] American National Standards Institute. 2012. "Personnel Certification Accreditation Workshop: Understanding the Requirements of ANSI/ISO/IEC 17024 - General requirements for bodies operating certification schemes for persons." https://www.ansica.org/wwwversion2/outside/PER17024course.asp?menuID=2.

Washington, D.C.: American National Standards Institute.

Brannick, M. T., Levine, E. L., \& Morgeson, F. P. 2007. Job and work analysis: Methods, research and applications for human resource management. Thousand Oaks, Calif.: Sage.

DACUM.org. 2001. "DACUM, An Online Resource for Occupational Analysis." http://www.dacum.org/. Quincy, Mass. DACUM.org. 
[DOE] United States Department of Energy. 2011. Job/Task Analysis for a Commercial Building Energy Auditor: Public Comment Draft. DOE/GO-102011-3427. Washington, D.C.: U.S. Department of Energy, Office of Energy Efficiency and Renewable Energy.

[NARA] National Archives and Records Administration. 2011. "Commercial Building Job/Task Analyses.” Federal Register 76 (199): 63913. Washington, D.C.: National Archives and Records Administration.

[NREL] National Renewable Energy Laboratory. 2012a. Commercial Building Energy Auditor Job/Task Analysis: Validation Report. SR-5500-55174. Golden, Colo.: National Renewable Energy Laboratory.

. 2012b. Commercial Building Energy Modeler Job/Task Analysis: Validation Report. SR5500-55179. Golden, Colo.: National Renewable Energy Laboratory.

. 2012c. Commissioning/Retro-Commissioning Authority Job/Task Analysis: Validation Report. SR-5500-55180. Golden, Colo.: National Renewable Energy Laboratory.

. 2012d. Energy/Sustainability Manager Job/Task Analysis: Validation Report. SR-550055177. Golden, Colo.: National Renewable Energy Laboratory.

. 2012e. Facility Manager Job/Task Analysis: Validation Report. SR-5500-55176. Golden, Colo.: National Renewable Energy Laboratory.

. 2012f. Operating Engineer/Building Technician Job/Task Analysis: Validation Report. SR5500-55175. Golden, Colo.: National Renewable Energy Laboratory.

[OSU] The Ohio State University. 2012. "DACUM Training Information." http://www.dacumohiostate.com/attend_dacum.htm. Columbus, Ohio: The Ohio State University.

Professional Testing, Inc. 2011. "Commercial Buildings National Guidelines Development." http://proftesting.rapidinsites.com/. Orlando, Fla.: Professional Testing, Inc.

Raymond, M.R. 2001. Job analysis and the specification of content for licensure and certification examinations. Applied Measurement in Education 14 (4): 369-415. 